\title{
Computer visualizations of architectural building illumination
}

\author{
S. Mroczkowska \\ Poznan University of Technology, \\ Institute of Electrical Engineering and Electronics, Poland
}

\begin{abstract}
Computer visualization has recently become an integral tool used in lighting design. Computer visualization is also a form of communication between a lighting designer and people not related to the industry of lighting technology. Generally, lighting projects are implemented on the basis of computer visualization of illumination. This paper presents the significance of computer visualization and illumination. Benefits of designing lighting based on computer visualization are described. The article also contains, out of theoretical consideration, various eye-realistic visualizations of architectural buildings. Keywords: lighting technology, illumination, computer visualization.
\end{abstract}

\section{Introduction}

The application of computer graphics can be seen in almost every area of life. Computer visualization in the field of lighting technology has recently become the inherent tool used in lighting design. Appropriate lighting equipment for a particular 3D model of illuminated object is selected. There are also many variants checked to obtain several most suitable illumination concepts. A lighting design, usually based on visualization, is completed with the use of lighting technology. The governing goal of photorealistic computer visualization is to present images generated by a computer to cause an impression of a real photograph. However, the main goal of illumination is to create an artificial image of the object by using light, to emphasize its attractiveness, draw attention to architectural details, embellish the surroundings and to ensure appropriate safety level. 


\section{Objects illumination}

The term "illumination" comes from the Latin word "illumino" which means "to light up", "to adorn". In recent years, the interest in illumination has increased. That is the effect of development in the area of lighting equipment but also the increase in social awareness of light, which plays a very important role with regard to safety and esthetics. As a result, illumination can be designed and realized in order to evoke emotional impressions, to shape mood or to ensure safety. Developing illumination concepts requires the assessment of:

- esthetic criteria which mainly determine the number of object observation directions, object location, historical significance of the object, façade characteristics,

- technical criteria related to the selection of appropriate lighting equipment and methods of arrangement and securing of luminaires,

- economic criteria related to the predicted costs of illumination investments,

- conservation criteria.

The illumination is realized using one of the three following methods [1]:

- flood lighting,

- spot lighting,

- mixed lighting, combining flood and spot lighting methods.

Until recently, flood lighting, a method which requires the use of small number of low-powered luminaires, has been used in the realization of architectural objects illumination. Due to the development in light sources, spot lighting, a method that requires the use of a large number of low-powered luminaires, is currently used more and more often. This method allows to realize illumination, which emphasizes with greater accuracy and accentuates architectural details of the object. The method also allows for a more comfortable use of the play of light and shadow $[1,4,5]$.

\section{Computer visualization}

The computer visualization of illumination consists in realistic reconstruction of objects in computer virtual space. There are many programs to create 3D graphics and they can be divided into two groups: modelers and renderers. The latter ones are used to visualize illumination as they generate three-dimensional images and allow applying textures and light effects [4]. Such programs include, e.g.: 3D Studio Max, LightWave 3D, 3D VIZ. The visualization may be also made in technically advanced light design programs, such as Relux Professional and DIALux.

The article presents the process of creating the visualization of an illuminated object in 3ds Max program. The work on computer visualization starts with creating the building's geometrical model, based on architectural plans or object photographs (figs. 1-3). Materials are applied to the existing grid to create the 


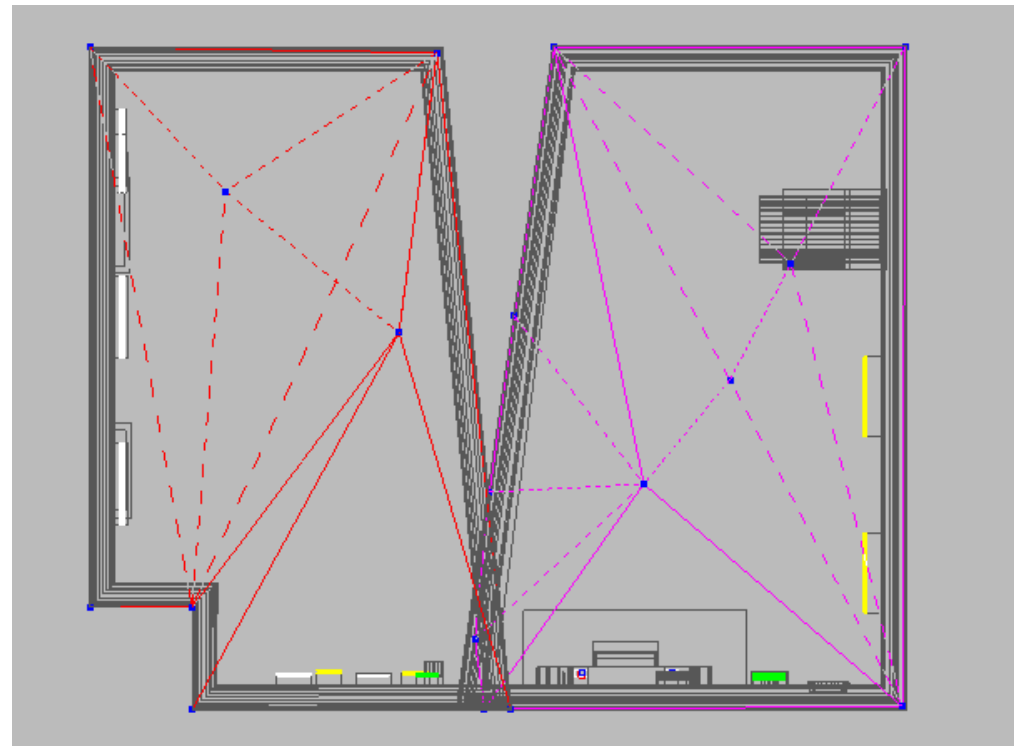

Figure 1: $\quad$ Model of object - top view.

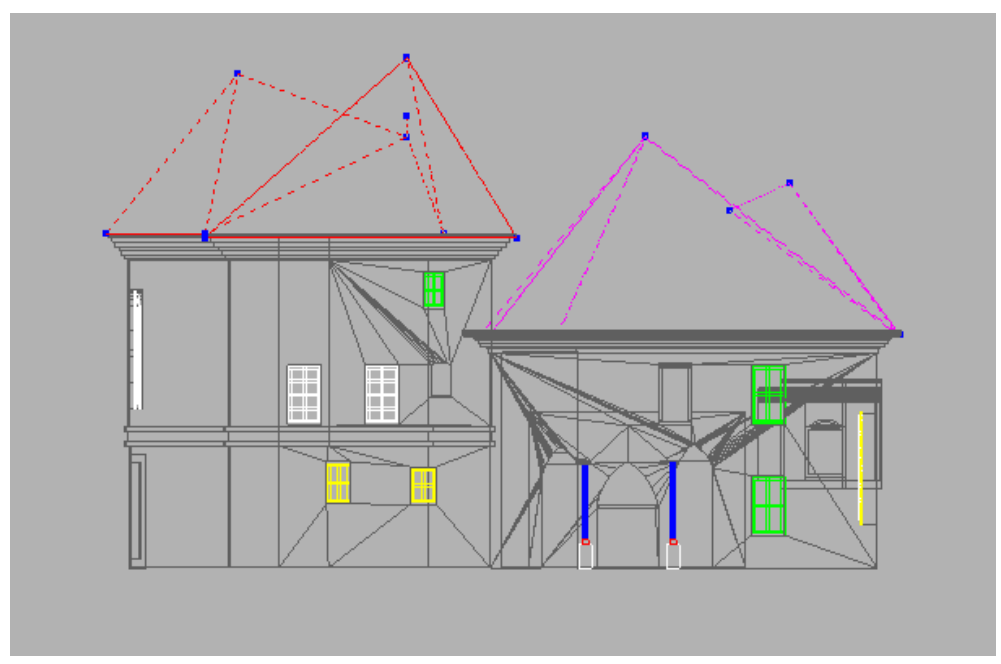

Figure 2: $\quad$ Model of object - front view.

building's texture (fig. 4). Computer visualization allows us to simulate the emission of light from a luminaire and the reflection or refraction of light from an illuminated surface.

Appropriate materials are selected and assigned to particular elements of a scene after the object model is designed and created. 
98 Lighting in Engineering, Architecture and the Environment

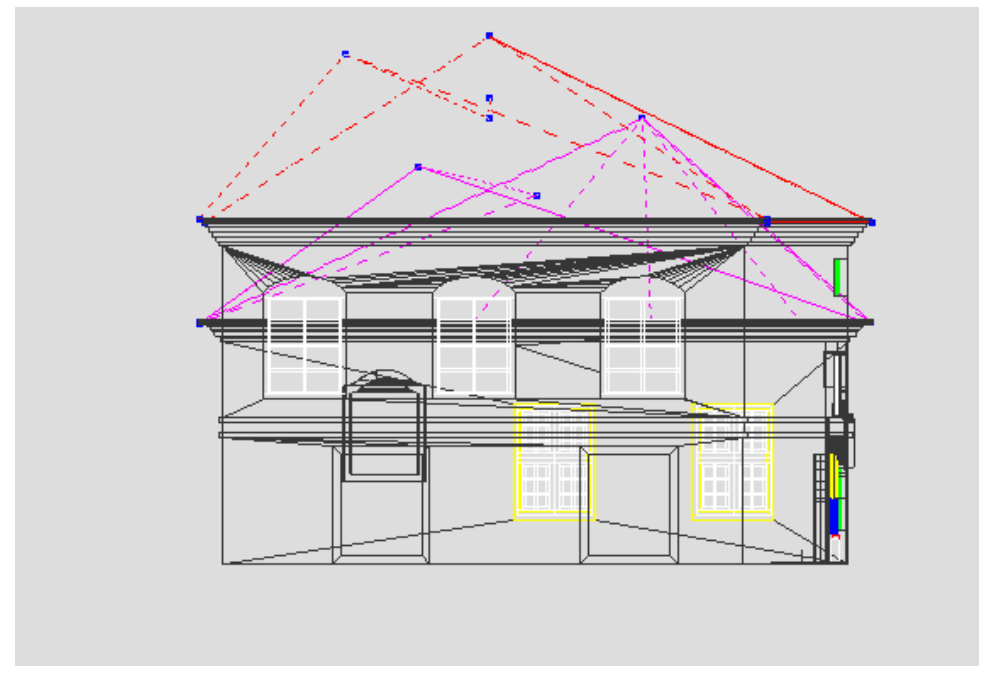

Figure 3: $\quad$ Model of object - left view.

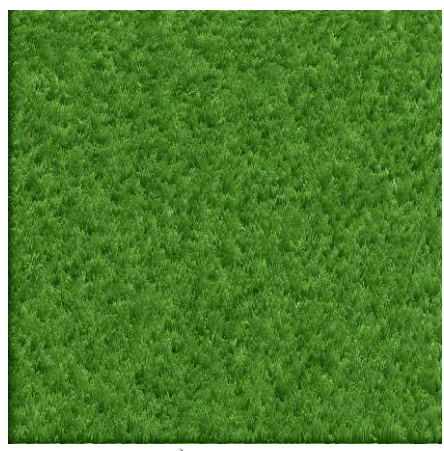

a)

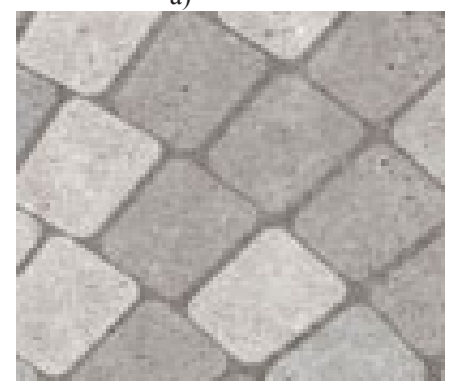

c)

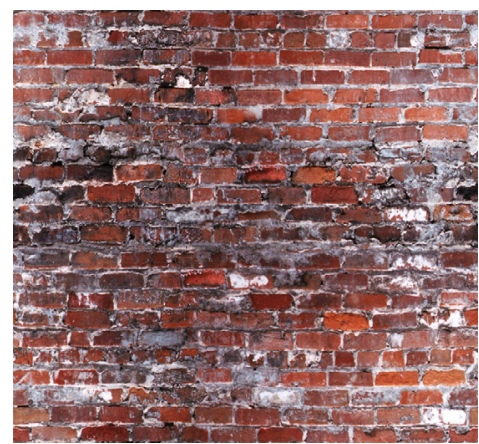

b)

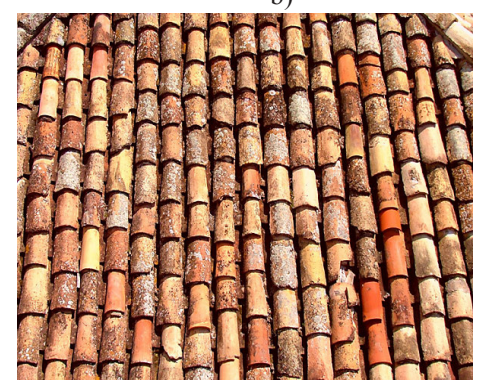

d)

Figure 4: Materials used to create the scene and the object a) grass, b) brick used as the object's façade texture, c) set stone, d) roof tile. 


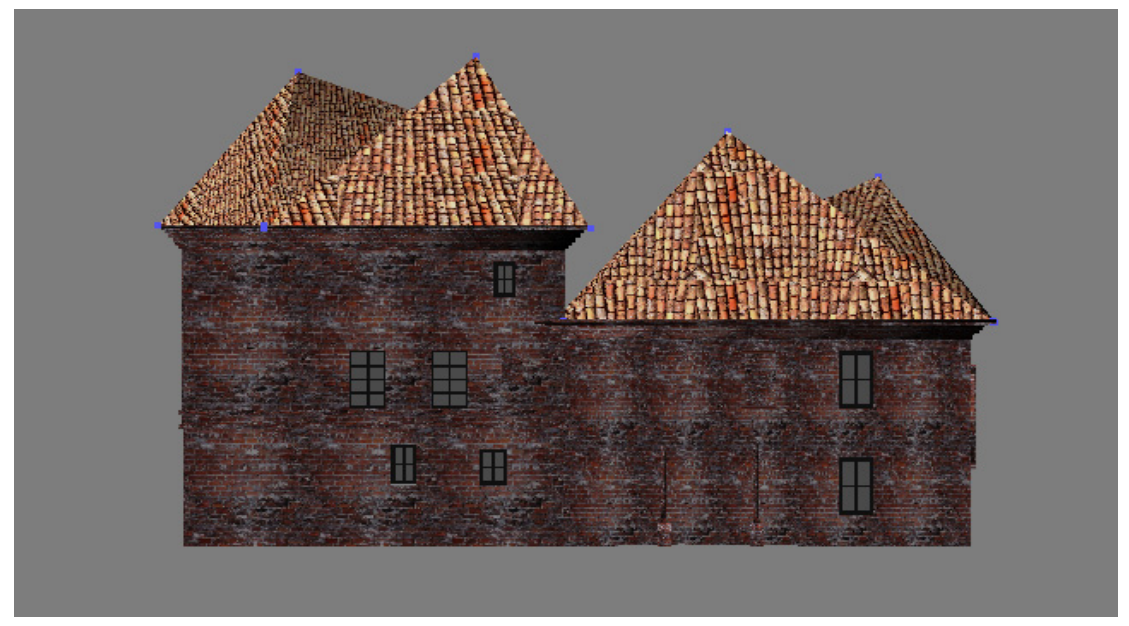

Figure 5: $\quad$ Model of object with assigned materials - front view.

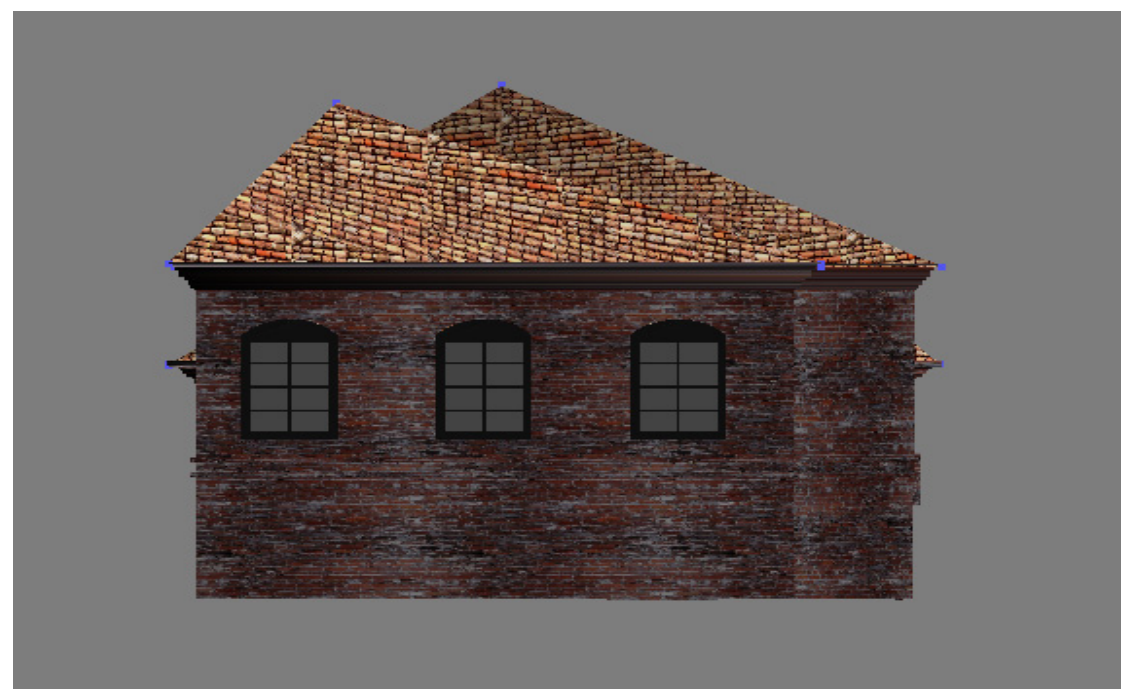

Figure 6: $\quad$ Model of object with assigned materials - left view.

There are many advantages to designing illumination by means of computer visualization. The fundamental benefit is the possibility of analyzing and testing many variants of illumination taking into accounts the object's architectural style, its dimensions and historical outline. In visualization, it is possible to test any amount of light equipment and to locate it in places that are inaccessible in the field. Changes that may take place in the future (e.g. façade color change) may be also taken into consideration when creating the object's geometrical model. Thanks to visualization it is also possible to control and minimize the amount of unwanted light in the environment, as well as to compare the way an 
object looks during the day and at night. When designing illumination with computer visualization, one may create any scene that illustrates the object's surroundings or accurately place a modeled object on a photograph in which adjacent buildings, sky, street, lamp posts, trees have really been photographed [1-3].

Graphic programs not only create photorealistic images of illuminated objects but also offer other advantages. It is possible to enter data, such as photometric solid of real luminaires, maximum luminous intensity, luminous flux, types of light sources and color temperature.

Computer visualization of illuminated objects requires from the designer both good knowledge of lighting technology, of computer graphics and the ability to model objects. This method of illumination concept presentation is particularly important for architectural illumination because it allows to predict virtually all light effects and to verify the amount and type of essential equipment.

\section{Illumination concepts}

Appropriate illumination equipment should be selected to achieve decorative illumination of an object. Several object illumination concepts may be analyzed during the realization of a project, and finally the best solution in terms of esthetics and economy may be chosen. Thanks to computer programs, it is possible to see the obtained effects of visualization from every direction and perspective, which is particularly important when designing illumination.

Object computer visualizations that depict three illumination concepts are presented in the article. The first variant was created with the use of sodium light

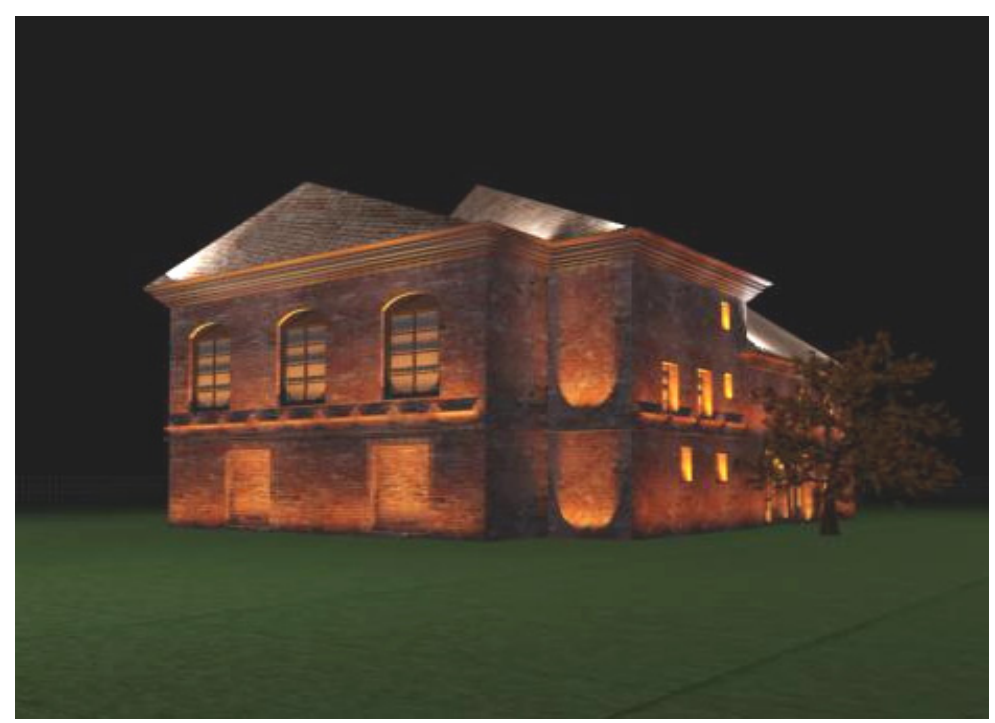

Figure 7: Computer visualization of illumination with the use of sodium light sources - perspective view. 


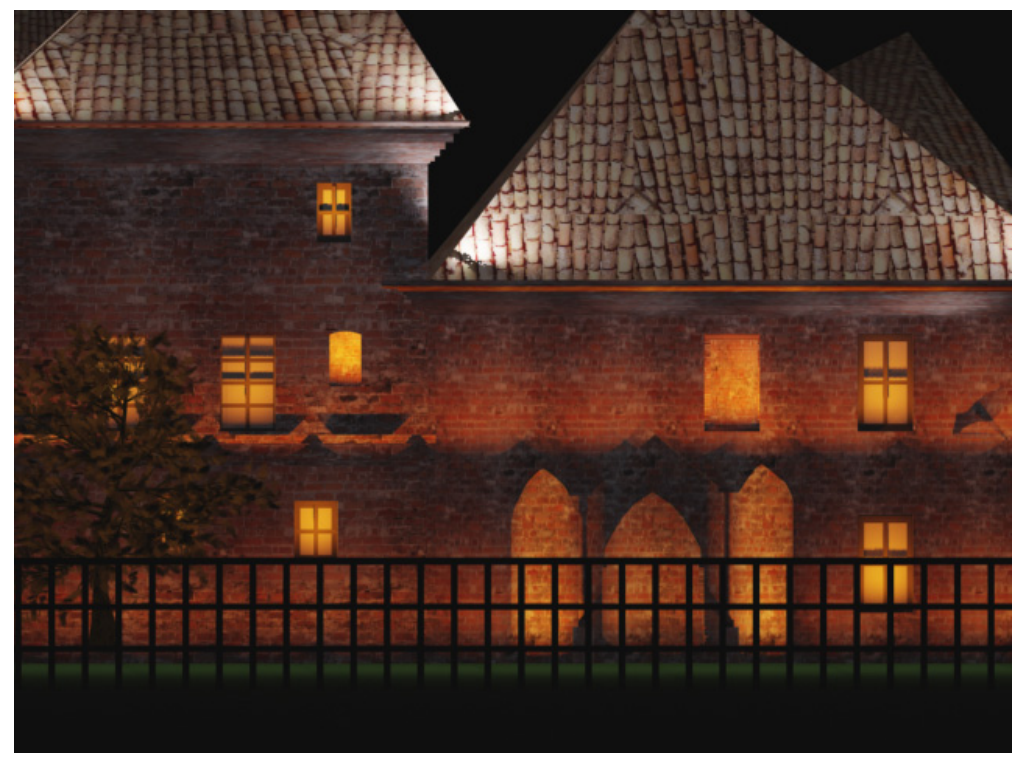

Figure 8: Computer visualization of illumination with the use of sodium light sources - front view.

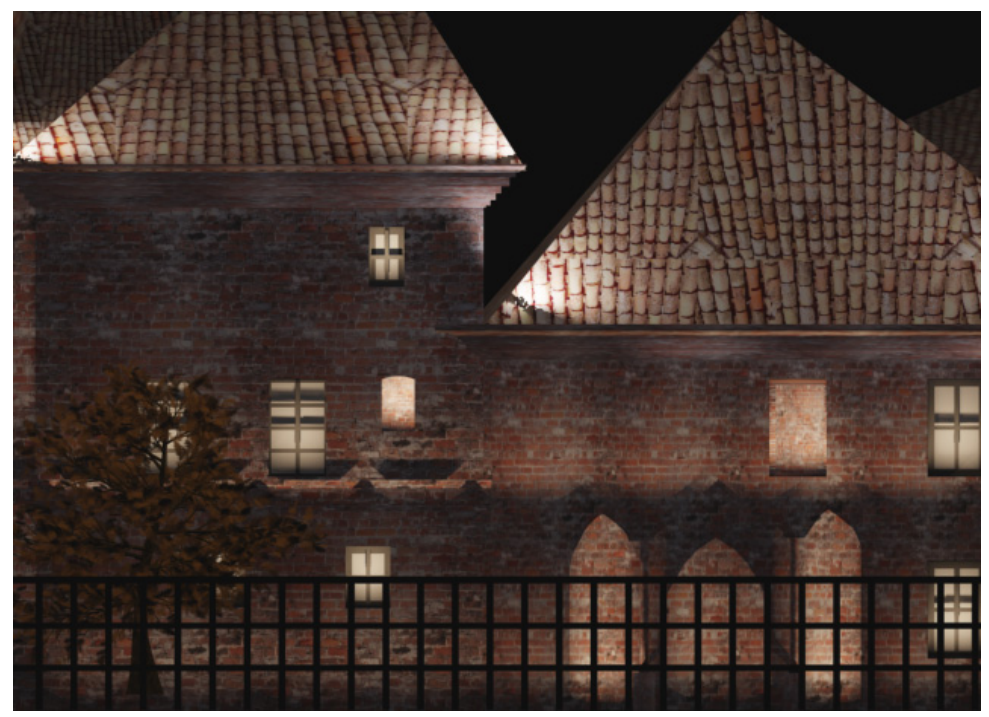

Figure 9: Computer visualization of illumination with the use of metal halide lamps - front view.

sources that intensified the "warm" impression of the building's brick facade. At the same time, the roof is illuminated with metal halide lamps (figs. 7 and 8). 


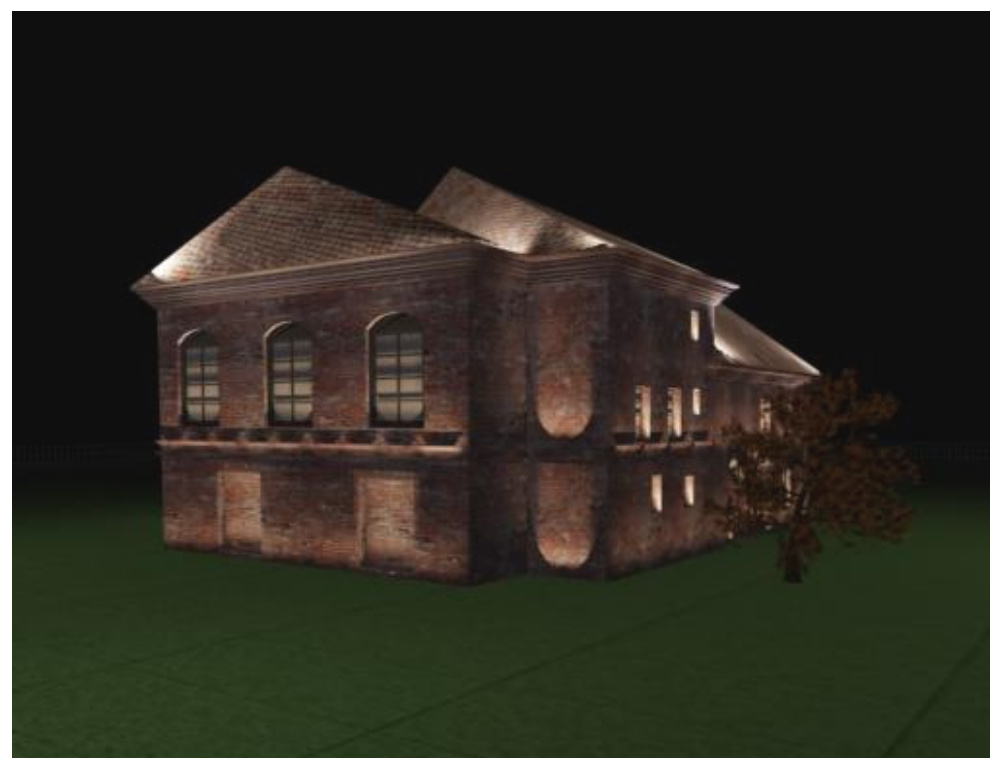

Figure 10: Computer visualization of illumination with the use of metal halide lamps - perspective view.

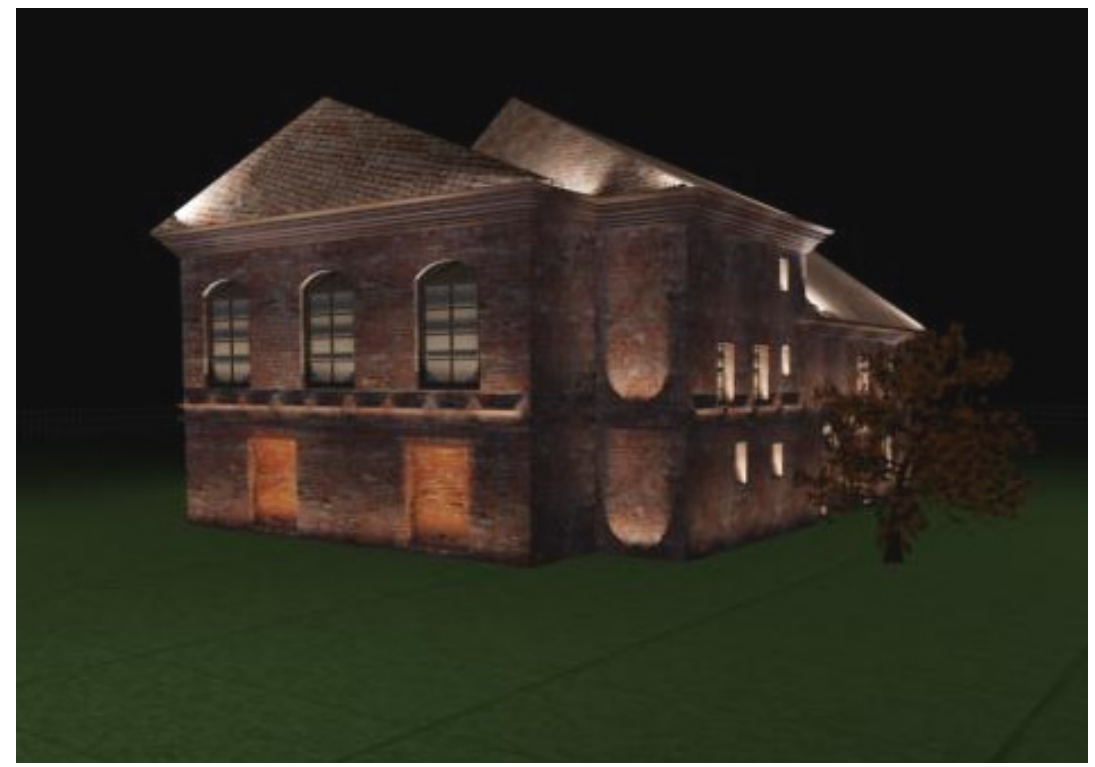

Figure 11: Computer visualization of an object illuminated with metal halide lamps and sodium lamps - perspective view. 
The second illumination concept presented in the form of computer visualization is based on the illumination of an object with metal halide lamps that cause the effect of whitening of the façade. The roof is also illuminated with metal halide lamps (figs. 9 and 10).

The third variant of object illumination assumes the use of sodium lamps and metal halide lamps. Various light colors for building illumination make the final image of object illumination definitely more attractive. In this case, object elevation is illuminated with metal halide lamps, whereas details in the form of alcoves are illuminated with sodium lamps (fig. 11).

The following figures present the simulation of the object's daily illumination. The surroundings of the building are enriched with grass, sett stone,

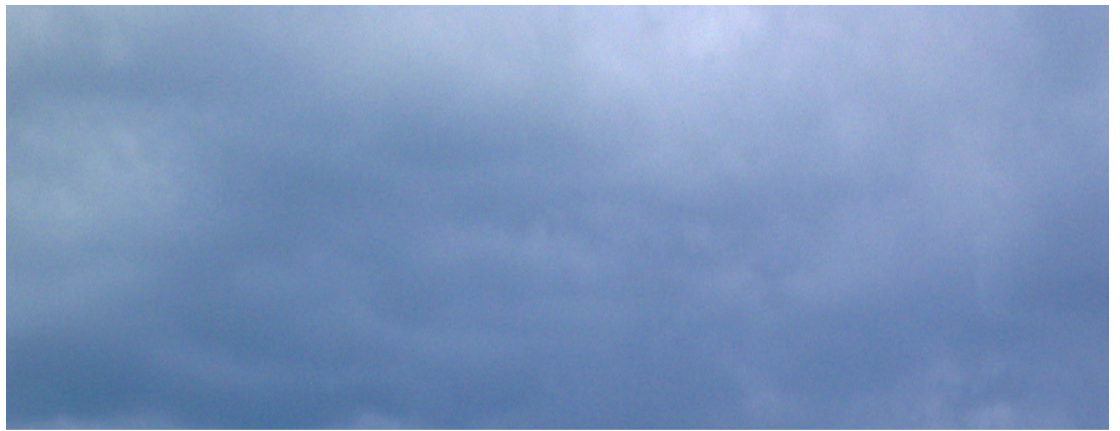

Figure 12: Photograph of the sky used in the background of object visualization.

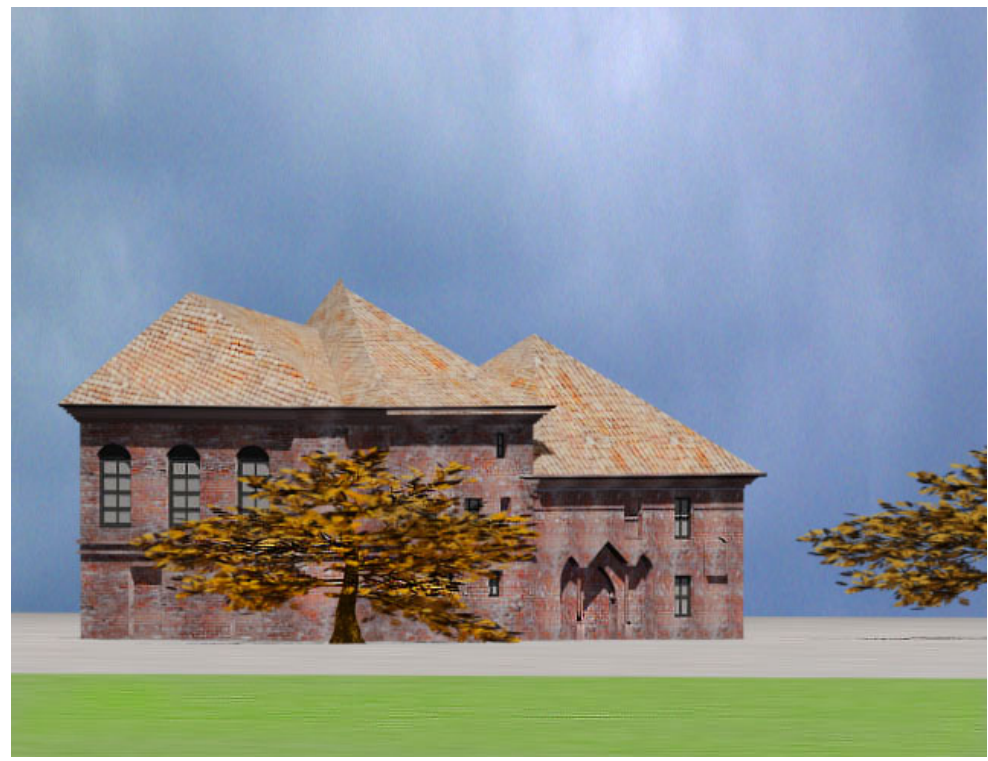

Figure 13: Simulation of daily illumination - perspective view. 


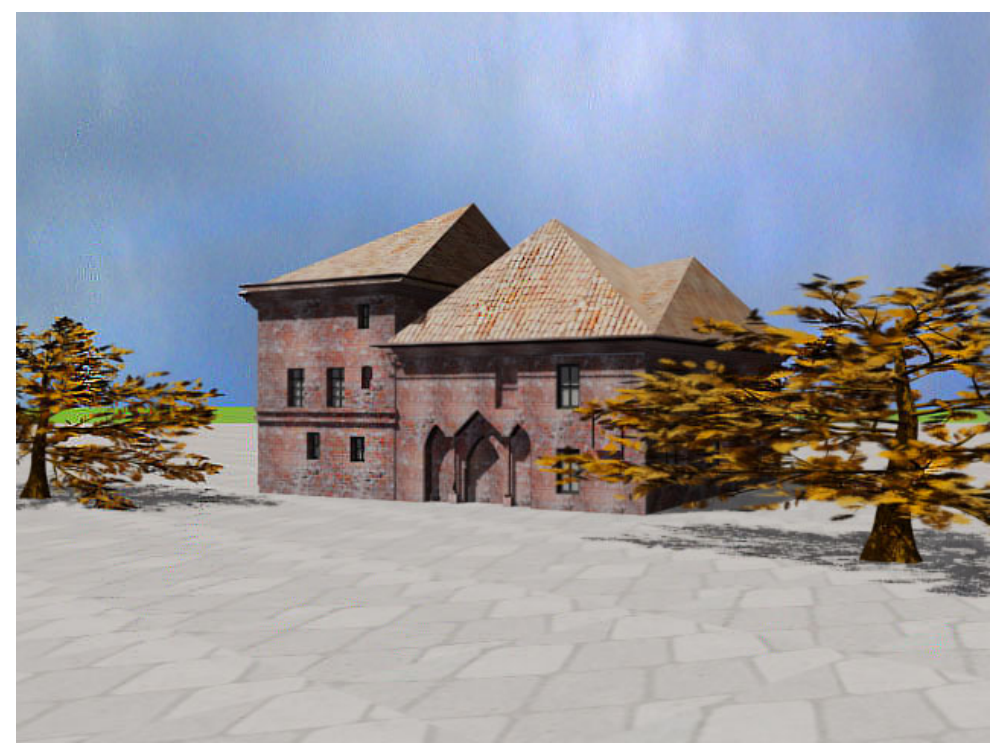

Figure 14: Simulation of daily illumination - perspective view.

trees, while the sky in the background has been pasted from a photograph (figs. 12 and 13).

\section{Conclusions}

Thanks to computer programs, it is possible to create many variants of visualization that present various illumination concepts. Computer visualization of objects illumination shows the image of the illuminated object. It also presents a building with all details and the play of light and shadow. All this allows to choose the most favorable and desirable version in final stage. Appropriate lighting equipment has to be selected to realize the visualization of decorative illumination. Each simulation of illumination is possible thanks to specific light beams and input data of the used equipment. At present, there are many manufacturers of luminaires and sources of light and this creates a lot of possibilities for selecting appropriate illumination equipment.

Computer visualization enables the assessment of the final esthetic effect of every version of illumination. The number of luminaires and the type of light sources can be verified. The final assessment of visual effect is always subjective; it is a matter of individual taste of the appraising person.

\section{References}

[1] Żagan, W., Iluminacja obiektów, Oficyna Wydawnicza Politechniki Warszawskiej: Warszawa, pp. 33-35, 2003.

[2] Steffy, G.R., Architectural Lighting Design, John Wiley \& Sons Inc.: New York, 2002. 
[3] Russell, S., The Architecture of Light: Architectural Lighting Design Concepts and Techniques: Conceptine, La Jola, CA, 2008.

[4] Górczewska, M., Polska szkoła iluminacji obiektów. Przegląd Elektrotechniczny, 9, pp.112-114, 2009.

[5] Żagan, W., Wasserfurth, N., Wizualizacja komputerowa oświetlenia - nowa jakość w projektowaniu. Przegląd Elektrotechniczny, 9, pp. 388-394, 2009. 